\title{
Renal Sympathetic Denervation Improves Cardiac Dysfunction in Rats With Chronic Pressure Overload
}

\author{
Z.-Z. LI ${ }^{1}$, H. JIANG ${ }^{1}$, D. CHEN ${ }^{2}$, Q. LIU ${ }^{1}$, J. GENG ${ }^{1}$, J.-Q. GUO ${ }^{1}$, R.-H. SUN ${ }^{1}$, G.-Q. ZHU ${ }^{2}$, \\ Q.-J. SHAN ${ }^{1}$
}

${ }^{1}$ Cardiovascular Department, First Affiliated Hospital of Nanjing Medical University, Nanjing, Jiangsu, China, ${ }^{2}$ Key Laboratory of Cardiovascular Disease and Molecular Intervention, Department of Physiology, Nanjing Medical University, Nanjing, Jiangsu, China

Received September 20, 2014

Accepted January 23, 2015

On-line March 24, 2015

\begin{abstract}
Summary
Varied causative and risk factors can lead to cardiac dysfunction. Cardiac dysfunction often evolves into heart failure by cardiac remodeling due to autonomic nervous system disturbance and neurohumoral abnormalities, even if the detriment factors are removed. Renal sympathetic nerve activity plays a pivotal regulatory role in neurohumoral mechanisms. The present study was designed to determine the therapeutic effects of renal sympathetic denervation (RSD) on cardiac dysfunction, fibrosis, and neurohumoral response in transverse aortic constriction (TAC) rats with chronic pressure overload. The present study demonstrated that RSD attenuated myocardial fibrosis and hypertrophy, and structural remodeling of the left atrium and ventricle, up-regulated cardiac $\beta$ adrenoceptor ( $\beta-A R$, including $\beta_{1} A R$ and $\left.\beta_{2} A R\right)$ and sarco-endoplasmic reticulum $\mathrm{Ca}^{2+}$-ATPase (SERCA) while down-regulated angiotensin II type 1 receptor $\left(A T_{1} R\right)$, and decreased plasma B-type natriuretic peptide (BNP), norepinephrine (NE), angiotensin II (Ang II), and arginine vasopressin (AVP) levels in TAC rats with chronic pressure overload. We conclude that RSD attenuates myocardial fibrosis, the left atrial enlargement, and the left ventricular wall hypertrophy; inhibits the overdrive of the sympathetic nervous system (SNS), renin-angiotensin-aldosterone system (RAAS), and AVP system in TAC rats with chronic pressure overload. RSD could be a promising non-pharmacological approach to control the progression of cardiac dysfunction.
\end{abstract}

\section{Key words}

Renal sympathetic denervation - Cardiac dysfunction • Remodeling

\section{Corresponding authors}

Q.-J. Shan, Chief of Electrophysiology Group, Cardiovascular Department, The First Affiliated Hospital of Nanjing Medical University, 300 Guangzhou Road, Nanjing, Jiangsu, 210029, China. Fax: +86-25-84352775. E-mail: qjshan@njmu.edu.cn and

G.-Q. Zhu, Key Laboratory of Cardiovascular Disease and Molecular Intervention, Department of Physiology, Nanjing Medical University, 140 Hanzhong Road, Nanjing, Jiangsu, 210029, China. Fax: +86-25-86862885. E-mail: gqzhucn@njmu.edu.cn

\section{Introduction}

Cardiac dysfunction can be caused by conditions that reduce cardiac output through ischemic damage, increased afterload, or restrictive disease such as myocardial infarction (MI), hypertension, and amyloidosis (Jackson et al. 2000, McMurray and Pfeffer 2005). Of note, neurohumoral abnormalities and disturbance of autonomic nervous system contribute to the process of cardiac remodeling and the transition to cardiac dysfunction (Bristow 1984, Lymperopoulos et al. 2013, Mann and Bristow 2005, Schrier and Abraham 1999). Renal sympathetic nerve activity plays a pivotal role in the regulation of neurohumoral mechanisms (DiBona and Sawin 2003, Sobotka et al. 2012, Zhang et al. 2012). The Symplicity-HTN3 trial failed to show a significant reduction in blood pressure (BP) in patients with resistant hypertension 6 months after renal sympathetic denervation (RSD) as compared with a sham control (Bhatt et al. 2014), but the effects of RSD on left 
ventricular hypertrophy and diastolic function might be beyond the improvement in BP (Brandt et al. 2012, Bruno and Taddei 2014, Schirmer et al. 2014). Jiang et al. (2012) showed that RSD can significantly delay the progression of left ventricular hypertrophy in spontaneously hypertensive rats (SHR). Hu et al. (2012, 2014) described the therapeutic effects of RSD on postMI cardiac remodeling in rats. The effects of RSD on cardiac dysfunction in transverse aortic constriction (TAC) rats with chronic pressure overload are unknown.

In response to chronic pressure overload by $\mathrm{TAC}$, the heart undergoes remodeling of the atrium and ventricle initially in an attempt to compensate for increased load. Hyperactivation of the neurohumoral axis is a hallmark of cardiac dysfunction, including hyperstimulation of the SNS, the RAAS, and AVP system. And that may ultimately lead to high levels of circulating catecholamines and $\beta$ adrenoceptor ( $\beta$-AR) stimulation to the myocardium (Rona 1985, Schmitz et al. 1996). In addition to its hemodynamic and metabolic effects, excessive response of neuroendocrine system has several direct detrimental effects on the myocardium, promoting cardiotoxic, adverse remodeling and cardiac dysfunction progression. Structural, neurohormonal, and electrical remodeling may encourage the progressive impairment of cardiac function subsequently.

The aim of the present study was designed to determine the therapeutic effects of RSD on the cardiac dysfunction, myocardial fibrosis and hypertrophy, structural remodeling of the left atrium and ventricle, and neurohumoral response in TAC rats with chronic pressure overload.

\section{Materials and Methods}

\section{Animals and experimental design}

All experiment procedures were approved by the Nanjing Medical University Experimental Animal Care and Use Committee and complied with the Guide for the Care and Use of Laboratory Animals (National Institutes of Health publication 8th edition, 2011). Sprague-Dawley rats weighting 250-300 g were purchased from Nanjing Medical University Laboratory Animal Center. All animals were caged in a room with controlled temperature and humidity with a 12-h light/dark cycle and provided a standard chow and drinking water ad libitum. Echocardiography was performed at week 0, 6, 10, 14. TAC and RSD (or sham operations) were carried out after echocardiography at week 0 and 6 , respectively.
See the study flow in supplementary Figure S1. At the end of the trial, after the fourth echocardiography and blood collection, all animals were euthanized with an overdose of intravenous pentobarbital sodium (200 mg/kg).

\section{Transverse aortic constriction}

TAC is widely used to induce cardiac dysfunction by pressure overload (Chen Y et al. 2013, Gelpi et al. 2011, Weinberg et al. 1994). Rats were anesthetized with a single intraperitoneal injection of pentobarbital sodium $(60 \mathrm{mg} / \mathrm{kg})$. The adequacy of anesthesia was monitored by loss of the pedal withdrawal reflex as previously reported (Chen WW et al. 2013). Through a right thoracotomy at the second intercostal space, a 3-0 silk suture was snared with the wire and pulled back around the ascending aorta. A bent 20-gauge needle was then placed next to the isolated aortic arch, and the suture was snugly tied around the needle and the aortic arch. After ligation, the needle was quickly removed. The skin was closed and the rats received an intramuscular (im) injection with 100000 IU of penicillin. All rats were ventilated with room air using with a rodent ventilator (683, Harvard Apparatus Inc, USA) and allowed to recover on a warming pad to minimize temperature variation until they were fully awake. The sham procedure was identical except that the aortic arch was not ligated.

\section{Renal sympathetic denervation}

Six weeks after TAC (or sham surgery), bilateral renal denervation or sham operations were performed in the three groups, under pentobarbital sodium $(60 \mathrm{mg} / \mathrm{kg}$ ip) anesthesia. The adequacy of anesthesia was monitored as mentioned above. Renal denervation was accomplished by a surgical-pharmacological procedure (Granger et al. 1996, Hu et al. 2012, Kassab et al. 1995). Mechanical denervation was performed by carefully stripping and cutting all visible nerves at $10 \mathrm{x}$ magnification along the renal arteries and veins from the aorta to the hilum of the kidney. Chemical denervation was performed by quickly painting the renal artery with $20 \%$ phenol in absolute ethanol. Then the artery was washed with isotonic saline. For sham denervation, the surgery was the same, but the renal artery and vein were not isolated and the nerves were left intact.

\section{ELISA}

Blood was collected into tubes containing EDTA, and then centrifuged at $3000 \mathrm{rpm}$ at $4{ }^{\circ} \mathrm{C}$ for 
$15 \mathrm{~min}$ to separate the plasma. Plasma was stored at $-80{ }^{\circ} \mathrm{C}$. Plasma B-type natriuretic peptide (BNP), norepinephrine (NE), angiotensin II (Ang II) and arginine vasopressin (AVP) levels at week 6 and 14 were determined using enzyme linked immunosorbent assay (ELISA) kits. All steps were carried out in accordance with the manufacturer's specifications (Uscn Life Science Inc, Wuhan, China).

\section{Echocardiography and hemodynamics}

Echocardiography was performed in all rats under ketamine (100 $\mathrm{mg} / \mathrm{kg}$ ip) anesthesia with Vevo2100 - a high resolution imaging system (VisualSonics, Canada) with a MS-250, 16.0-21.0 MHz imaging transducer. BP measurement was performed in non-anesthetized rats with a non-invasive multi-channel tail-cuff system (BP 2000, Visitech) before TAC (week 0), before RSD (week 6), and at the end of the study (week 14).

\section{Samples and staining}

Blood was collected as described above. Animals were sacrificed with an overdose of pentobarbital sodium $(200 \mathrm{mg} / \mathrm{kg}$ iv). All rat hearts were weighed and washed with ice-cold PBS. The apices of the hearts were clipped and subsequently immersed in paraformaldehyde at $4{ }^{\circ} \mathrm{C}$ for $48-72 \mathrm{~h}$, then embedded in paraffin for histopathology examinations. The remainder of the hearts was stored at $-80^{\circ} \mathrm{C}$. As in our previous study (Zhang et al. 2012), the cross-sectional area of cardiomyocytes and the total interstitial fibrosis in the myocardium were quantitatively analyzed by morphometry in hematoxylin and eosin (HE) and Masson's trichrome-stained sections, respectively. Five fields were randomly selected for evaluating the microscopic morphology of the heart. The percent area of interstitial fibrosis was determined by the ratio of the blue fibrosis area to the total myocardial area.

\section{Quantitative RT-PCR and Western blot}

Total RNA was extracted from the same part of heart (left ventricular free wall) with Trizol reagent (Invitrogen, USA). cDNA in each sample was synthesized using a Primescript Reverse Transcriptase Kit (Takara Bio, Japan) and PCR-amplification performed using a Premix Ex $\mathrm{Taq}^{\mathrm{TM}}$ Kit (Takara Bio) according to the manufacturer's instructions on the SteponePlus System. The PCR reaction was performed in a volume of $10 \mu \mathrm{l}\left(5.0 \mu \mathrm{l} \mathrm{SyBR}\right.$ Premin Ex Taq ${ }^{\mathrm{TM}} \mathrm{II}$; $3.6 \mu \mathrm{l}$ water; $0.2 \mu \mathrm{l}$ forward primer and reverse primer, and $1 \mu \mathrm{l}$ geomic DNA). The primer (Invitrogen) sequences are shown in Table 1. Analysis of relative gene expression levels was performed using the following formula $2^{-\Delta \mathrm{CT}}$ with $\Delta \mathrm{CT}=\mathrm{CT}_{\text {(target gene) }}-\mathrm{CT}_{\text {(control). }}$ The expressions of $\beta_{1} \mathrm{AR}, \beta_{2} \mathrm{AR}$ and SERCA proteins in the myocardium were detected by Western blot analysis. All proteins were normalized to glyceraldehyde-3-phosphate dehydrogenase (GAPDH, 34 kDa, 1/3000-5000, Abmart, Shanghai, China). All antibodies were applied according to the manufacturer's instructions (Abcam Inc, UK). The dilution ratios of antibodies were as follow: $\beta_{1} \mathrm{AR}$, $50 \mathrm{kDa}, 1 / 1000 ; \beta_{2} \mathrm{AR}, 46 \mathrm{kDa}, 1 / 500$; SERCA, $115 \mathrm{kDa}$, $1 / 1000$, and $\mathrm{AT}_{1} \mathrm{R}, 41 \mathrm{kDa}, 1 / 800$.

\section{Kaplan-Meier survival analysis}

Survival over the 14-week experiment was analyzed according to the daily recording of deaths by the standard Kaplan-Meier analysis with the log rank test.

Table 1. Primer sequences used in $q R T-P C R$ reactions.

\begin{tabular}{lll}
\hline Target & Primer sequences & Reference \\
\hline \multirow{2}{*}{$\beta_{1} A R$} & F 5'-CGC TCA CCA ACC TCT TCA TCA TGTCC-3' & \\
& R 5'-CAG CAC TTG GGG TCG TTG TAG GAG C-3' & (Troispoux et al. 1998) \\
$\beta_{2} A R$ & F 5'-TCT TCG AAA ACC TAT GGG AAC GGC-3' & (Troispoux et al. 1998) \\
SERCA & R 5'-GGA TGT GCC CCT TCT GCA AAA TCT-3' & \\
& F 5'-AGT GGC TGA TGG TGC TGA AA-3' & (Fredersdorf et al. 2012) \\
GAPDH & R 5'-GCA CCC GAA CAC CCT TAC AT-3' & \\
& F 5'-GAT GCT GGT GCT GAG TAT GTCG-3' & (Fort et al. 1985, Zhao et al. 1995) \\
\hline
\end{tabular}

$\beta_{1} A R=\beta_{1}$ adrenergic receptor; $\beta_{2} A R=\beta_{2}$ adrenergic receptor; SERCA = sarco-endoplasmic reticulum $\mathrm{Ca}^{2+}$-ATPase; $F=$ forward primer; $\mathrm{R}=$ reverse primer; $\mathrm{GAPDH}=$ glyceraldehyde-3-phosphate dehydrogenase 

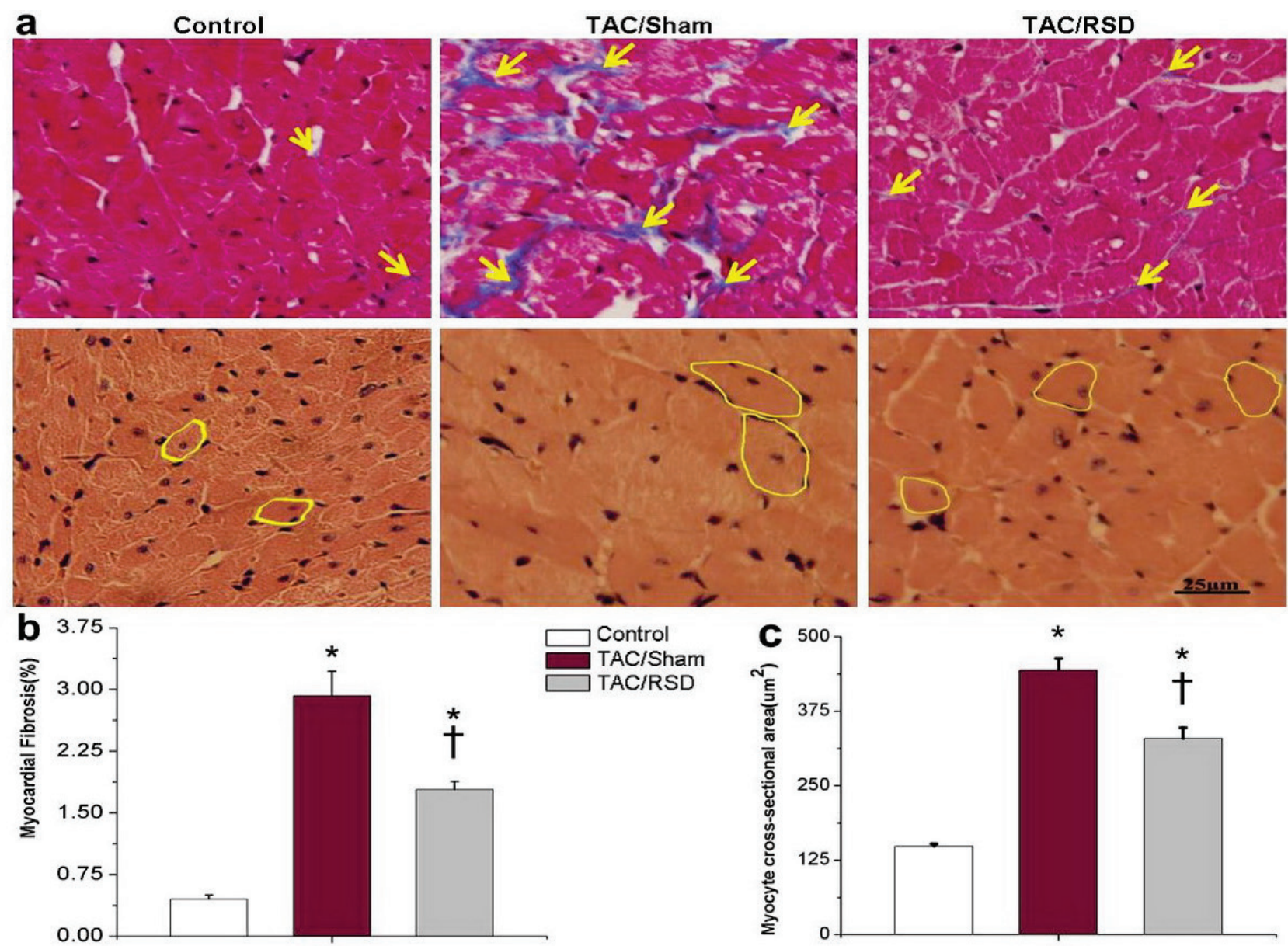

Fig. 1. Myocardial fibrosis and myocyte cross-sectional area. Sections showing myocardial fibrosis (the blue area of yellow arrows) with Masson's trichrome staining and cross-sections of cardiomyocytes with hematoxylin and eosin (HE) staining, respectively $(\times 400),(a)$. Bar graph showing quantitative myocardial fibrosis (b), and myocyte cross-sectional area (c). Values are the mean $\pm S E$. $n=5$ for each group. * $\mathrm{P}<0.05$ vs. Control group, $+\mathrm{P}<0.05$ vs. TAC/Sham group

\section{Statistics}

All continuous variables are expressed as the means $\pm \mathrm{SE}$ except the data of survival analysis and analyzed using SPSS 16.0. (SPSS Inc, Chicago, IL, USA). Comparisons between the two groups performed made by Student's t-test. ANOVA was used for multiple comparisons. A value of $\mathrm{P}<0.05$ was considered statistically significant.

\section{Results}

\section{Myocardial remodeling}

Longstanding pressure overload results in increased myocardial fibrosis and hypertrophy. The cross-sectional area of cardiomyocytes and myocardial interstitial fibrosis were blunted by RSD which were increased by TAC (Fig. 1).

\section{Plasma BNP, NE, Ang II and AVP levels}

Persistent TAC caused a neurohumoral response consisting of the SNS, RAAS, and AVP system. RSD presented inhibitory effects on the neurohumoral response. The final plasma BNP, NE, Ang II, and AVP levels in TAC/RSD rats were significantly decreased compared with TAC/Sham rats (Fig. 2).

\section{$m R N A$ and protein levels}

The cardiac adrenergic receptor system (CARS) was altered due to continuously increased global sympathetic tone and high levels of circulating catecholamines. The decreased expression of mRNA and protein levels of myocardial $\beta_{1} A R, \beta_{2} A R$, and SERCA by TAC were up-regulated by RSD at different levels while the increased protein level of cardiac $\mathrm{AT}_{1} \mathrm{R}$ was downregulated by RSD (Fig. 3).

\section{Echocardiography and hemodynamics}

Structural remodeling of the left atrium and ventricle was inevitable in response to the prolonged hemodynamic overload. At week 10 (4 weeks after RSD 
or sham surgery), the left atrial diameter (LAD), interventricular septal thickness (IVSTd) and left ventricular posterior wall in diastole (LVPWd) were significantly improved by RSD in TAC/RSD rats compared with the TAC/Sham rats. The improvement of
RSD was attenuated at week 14. The tail-cuff BP was significantly decreased by in the two TAC groups compared with the Control group but there were no significant changes after RSD or sham surgery between the three groups (Table 2).
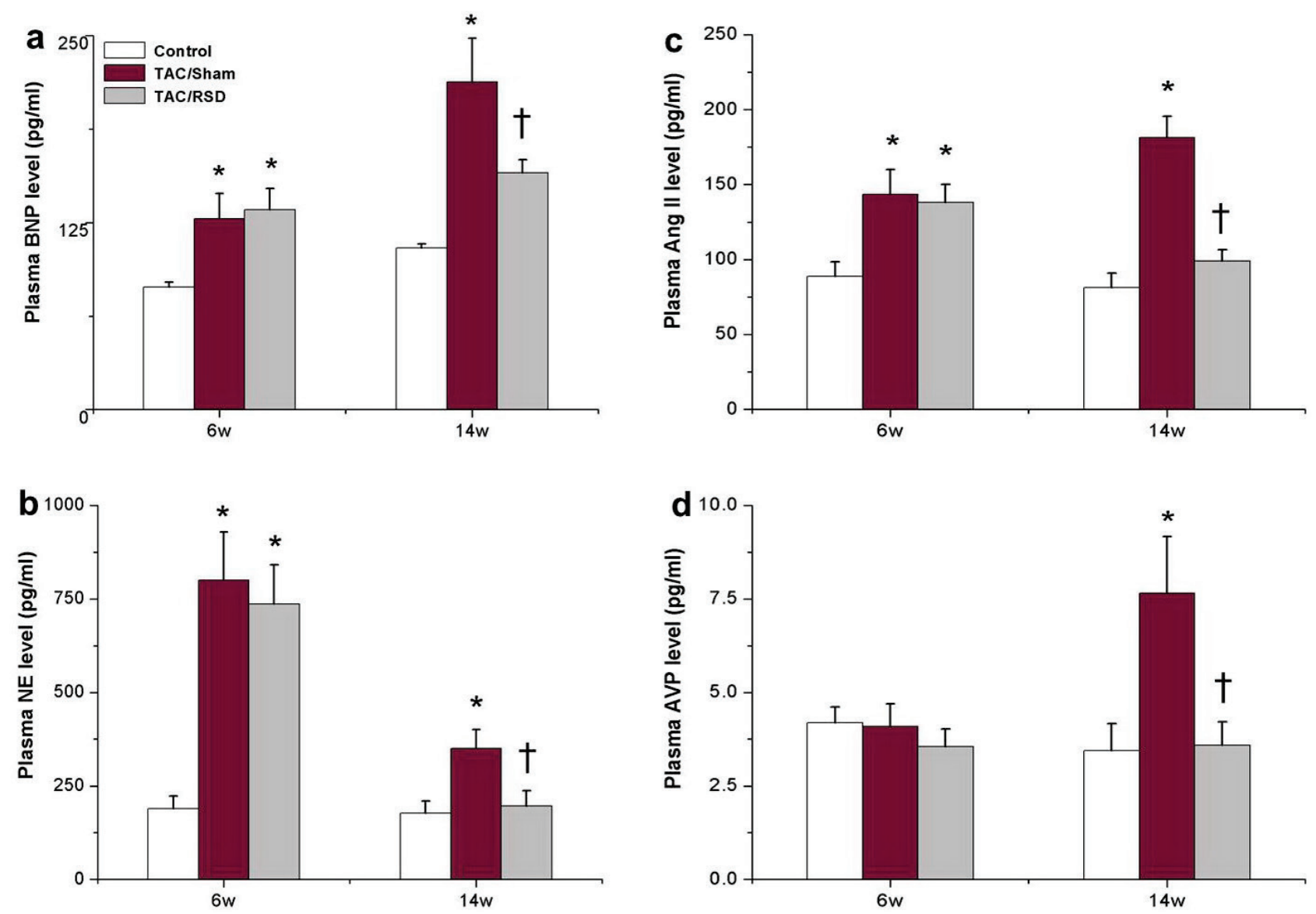

Fig. 2. Changes in plasma BNP (a), NE (b), Ang II (c) and AVP (d) levels. Values are the mean $\pm S E$. $n=6$ for each group. $* P<0.05$ vs. Control group, $+\mathrm{P}<0.05$ vs. $\mathrm{TAC} /$ Sham group. $\mathrm{BNP}=\mathrm{B}$-type natriuretic peptide; $\mathrm{NE}=$ norepinephrine; $\mathrm{Ang}$ II $=$ angiotensin II; $\mathrm{AVP}=$ arginine vasopressin

\section{Kaplan-Meier survival analysis}

During the follow-up in the current experiment, 17 of 20 animals died in the untreated TAC/Sham group compared with 9 of 20 animals in the TAC/RSD group. One of ten in the Control group died. As shown in supplementary Figure S2, during the follow-up in the current study, the survival was improved in trend by RSD compared with the untreated TAC/Sham group with no statistics difference.

\section{Discussion}

The TAC model is widely used to induce cardiac dysfunction by chronic pressure overload. Cardiac dysfunction will continue developing due to the prolonged hemodynamic overload, the subsequent increased global sympathetic tone, and intrinsically decreased contractile function. Ultimately, those changes result in high levels of circulating catecholamines and excessive stimulation of $\beta$-AR and $\mathrm{AT}_{1} \mathrm{R}$ to the myocardium (Kiuchi et al. 1993, Rona 1985, Schmitz et al. 1996). The direct cardiotoxic effects above lead to the structural, neurohormonal, and electrical remodeling to compensate initially, but finally they contribute to the progressive impairment of cardiac function. In the current study, the myocardial fibrosis and hypertrophy by gradual pressure overload was attenuated by RSD in the TAC/RSD group (Fig. 1). The left atrial enlargement and left ventricular wall hypertrophy induced by TAC were markedly improved by RSD at week 10 even though the 


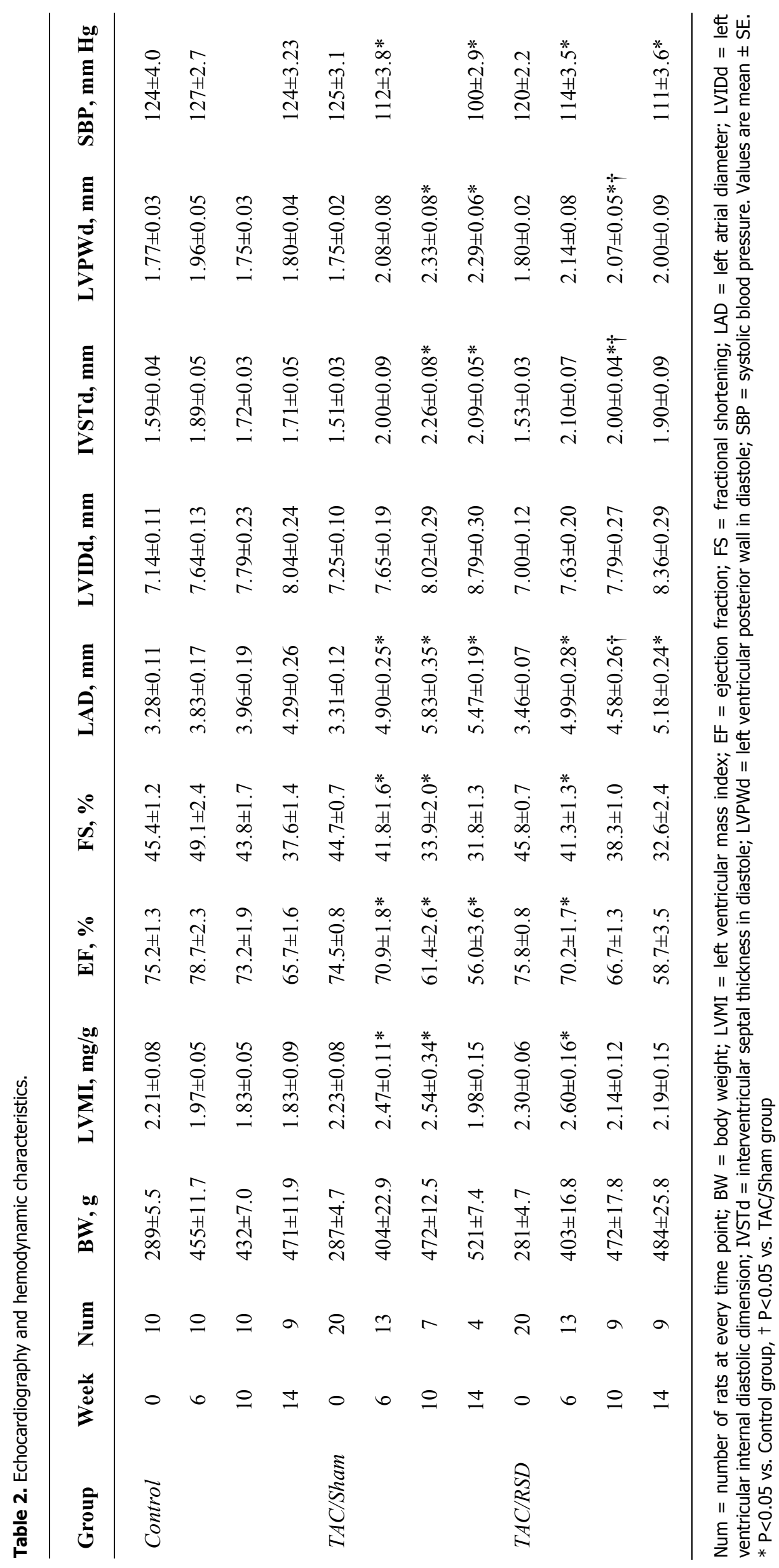


improvement was blunted at the end of the study (Table 2). The increased left ventricular mass by chronic pressure overload was decreased by RSD within TAC animals and sustained for at least four weeks (supplementary Fig. S3). These main results of effects on cardiac remodeling were consistent with previous studies on SHR or post-MI rats (Hu et al. 2012, 2014, Jiang et al. 2012). In our study, the increased left ventricular internal diastolic dimension (LVIDd) by TAC was improved by RSD but without significance. The left ventricular mass in TAC/Sham group was plummeted in the end of the study. These findings might be related to the transformation of cardiac function status from compensatory hypertrophy to decompensated hypertrophy, unlike dilated cardiomyopathy induced by chronic pacing.

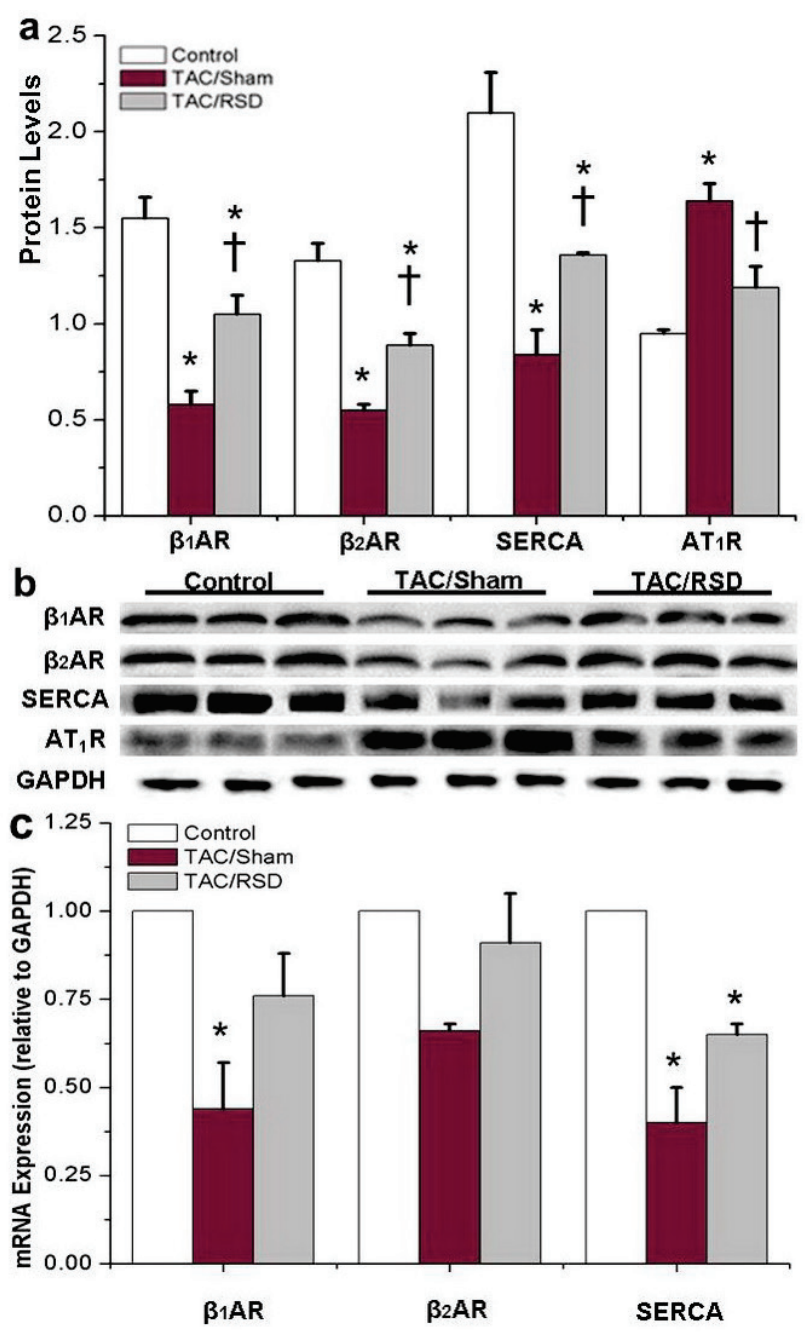

Fig. 3. Changes in mRNA and protein levels. Bar graph showing the expression of mRNA levels (a) and protein levels (b) of cardiac $\beta_{1}, \beta_{2}$, SERCA and $A T_{1} R$ normalized to GAPDH. Western blot showing the protein band (c). Values are the mean $\pm \mathrm{SE}$. $\mathrm{n}=3$ for each group. $* \mathrm{P}<0.05$ vs. Control group, $+\mathrm{P}<0.05$ vs. TAC/Sham group
As discussed above, one consequence of exposing cardiomyocytes to high concentrations of circulating catecholamines is an alteration in cardiac adrenergic receptor pharmacology. The $\beta$-AR signaling pathway plays a pivotal regulatory role in response to catecholamines in CARS. The proportional and functional alteration of $\beta$-AR signaling produces desensitization of downstream responses and ultimately affects the SERCA, which mediates $\mathrm{Ca}^{2+}$ re-uptake into the sarcoplasmic reticulum in cardiomyocytes (Port and Bristow 2001). As a consequence, these changes decrease the sensitivity of cardiomyocytes to catecholamines. In the current study, we have observed that RSD increased myocardial $\beta$-AR and SERCA at different levels in the dysfunctional hearts of TAC animals. However, these inhibitory effects were independent of BP changes, these are consistent with previous studies (Brandt et al. 2012, Schirmer et al. 2014). These anti-adrenergic effects of RSD on SNS or CARS are direct and proactive, which differ from the pharmacological sympatholytic agents, such as $\beta$-AR antagonists.

The pathogenesis of cardiac dysfunction involves excessive activation of the neurohumoral axis including stimulation of the SNS, the RAAS, and AVP system (Schrier 2006). The levels of circulating NE, AVP and Ang II increased as a result of the overdrive of SNS and RAAS. It has been shown that Ang II acts primarily on the pre-synaptic nerve terminal $\mathrm{AT}_{1} \mathrm{R}$ to modulate release of NE (Balt et al. 2001, DiBona 2000). Angiotensin-converting enzyme inhibitors (ACEIs) and angiotensin receptor blockers (ARBs), by decreasing Ang II and aldosterone levels, decrease circulating catecholamines and vasopressin because of the hemodynamic improvements they bring about. As expected, excessive activation of neurohumoral response induced by gradual pressure overload was attenuated by RSD within TAC animal models. RSD down-regulated the expression of $\mathrm{AT}_{1} \mathrm{R}$ in the myocardium, simultaneously, decreased the high levels of plasma BNP, $\mathrm{NE}$, and Ang II in TAC animals with chronic pressure overload. In this way, RSD attenuates the direct cardiotoxic, detrimental effects on the myocardium due to excessive activation of neurohumoral response. These are the inhibitory effects of RSD intervention on the involvement of systemic SNS and intrarenal RAAS. This finding is similar to a recent study on a transgenic rat model of diabetic nephropathy (Yao et al. 2014). As we know, RAAS plays a vital regulatory role in the synthesis and release of AVP. AVP causes anti-diuresis by 
activating vasopressin $V_{2}$ receptors on the basolateral surface of the principal cells in the collecting duct and after a set of cascade reactions, the water channels, which allow a single file of water molecules to traverse the apical membrane, was translocated to increase water absorption (Nielsen et al. 1995). Moreover, AVP can also activate vasopressin $\mathrm{V}_{1}$ receptors in vascular smooth muscle which may contribute to cardiac dysfunction (Johnston et al. 1986, Naitoh et al. 1994). If conditions persist, cardiac dysfunction induced by chronic pressure overload probably transits into volume overload.

We should acknowledge that the effects of RSD on TAC animal models were languishing in the end despite the considerable effects at week 10 in our study. The following factors are notable: the on-going persistence of the aortic arch ligation; the intrinsically deteriorating cardiac dysfunction along with TAC; and the survival bias (more sick animals died). These all may be closely related to the limited improvement of survival. We conclude that the therapeutic effects of RSD on cardiac function, myocardial fibrosis and hypertrophy, structural remodeling of atrium and ventricle, and neurohumoral response reported in this study provide scientific support for the application of RSD procedures in cardiac dysfunction caused by chronic pressure overload. As a minimally invasive therapy, RSD is a promising non-pharmacological strategy to control the progression of cardiac dysfunction.

\section{Conflict of Interest}

There is no conflict of interest.

\section{Acknowledgements}

The work was supported by the Natural Science Fund of Health Administration of Jiangsu Province (No.H201302), the Priority Academic Program Development of Jiangsu Higher Education Institutions, and the Novel Technology Fund of the First Affiliated Hospital of Nanjing Medical University (No.2012017).

\section{References}

BALT JC, MATHY MJ, NAP A, PFAFFENDORF M, VAN ZWIETEN PA: Effect of the AT1-receptor antagonists losartan, irbesartan, and telmisartan on angiotensin II-induced facilitation of sympathetic neurotransmission in the rat mesenteric artery. $J$ Cardiovasc Pharmacol 38: 141-148, 2001.

BHATT DL, KANDZARI DE, O'NEILL WW, D'AGOSTINO R, FLACK JM, KATZEN BT, LEON MB, LIU M, MAURI L, NEGOITA M, COHEN SA, OPARIL S, ROCHA-SINGH K, TOWNSEND RR, BAKRIS GL; SYMPLICITY HTN-3 INVESTIGATORS: A controlled trial of renal denervation for resistant hypertension. N Engl J Med 370: 1393-1401, 2014.

BRANDT MC, MAHFOUD F, REDA S, SCHIRMER SH, ERDMANN E, BOHM M, HOPPE UC: Renal sympathetic denervation reduces left ventricular hypertrophy and improves cardiac function in patients with resistant hypertension. J Am Coll Cardiol 59: 901-909, 2012.

BRISTOW MR: The adrenergic nervous system in heart failure. $N$ Engl J Med 311: 850-851, 1984.

BRUNO RM, TADDEI S: Renal denervation and regression of left ventricular hypertrophy. Eur Heart J 35: 2205 $2207,2014$.

CHEN WW, SUN HJ, ZHANG F, ZHOU YB, XIONG XQ, WANG JJ, ZHU GQ: Salusin- $\beta$ in paraventricular nucleus increases blood pressure and sympathetic outflow via vasopressin in hypertensive rats. Cardiovasc Res 98 : 344-351, 2013.

CHEN Y, LI Y, GUO L, CHEN W, ZHAO M, GAO Y, WU A, LOU L, WANG J, LIU X, XING Y: Effects of wenxin keli on the action potential and L-type calcium current in rats with transverse aortic constriction-induced heart failure. Evid Based Complement Alternat Med 2013: 572078, 2013.

DIBONA GF: Nervous kidney. Interaction between renal sympathetic nerves and the renin-angiotensin system in the control of renal function. Hypertension 36: 1083-1088, 2000.

DIBONA GF, SAWIN LL: Frequency response of the renal vasculature in congestive heart failure. Circulation 107: 2159-2164, 2003.

FORT P, MARTY L, PIECHACZYK M, EL SABROUTY S, DANI C, JEANTEUR P, BLANCHARD JM: Various rat adult tissues express only one major mRNA species from the glyceraldehyde-3-phosphate-dehydrogenase multigenic family. Nucleic Acids Res 13: 1431-1442, 1985. 
FREDERSDORF S, THUMANN C, ZIMMERMANN WH, VETTER R, GRAF T, LUCHNER A, RIEGGER GA, SCHUNKERT H, ESCHENHAGEN T, WEIL J: Increased myocardial SERCA expression in early type 2 diabetes mellitus is insulin dependent: in vivo and in vitro data. Cardiovasc Diabetol 11: 57, 2012.

GELPI RJ, PARK M, GAO S, DHAR S, VATNER DE, VATNER SF: Apoptosis in severe, compensated pressure overload predominates in nonmyocytes and is related to the hypertrophy but not function. Am J Physiol Heart Circ Physiol 300: H1062-H1068, 2011.

GRANGER J, NOVAK J, SCHNACKENBERG C, WILLIAMS S, REINHART GA: Role of renal nerves in mediating the hypertensive effects of nitric oxide synthesis inhibition. Hypertension 27: 613-618, 1996.

HU J, JI M, NIU C, AINI A, ZHOU Q, ZHANG L, JIANG T, YAN Y, HOU Y: Effects of renal sympathetic denervation on post-myocardial infarction cardiac remodeling in rats. PloS One 7: e45986, 2012.

HU J, YAN Y, ZHOU Q, JI M, NIU C, HOU Y, GE J: Effects of renal denervation on the development of postmyocardial infarction heart failure and cardiac autonomic nervous system in rats. Int J Cardiol 172: e414-e416, 2014.

JACKSON G, GIBBS CR, DAVIES MK, LIP GY: ABC of heart failure. Pathophysiology. BMJ 320: 167-170, 2000.

JIANG W, TAN L, GUO Y, LI X, TANG X, YANG K: Effect of renal denervation procedure on left ventricular hypertrophy of hypertensive rats and its mechanisms. Acta Cir Bras 27: 815-820, 2012.

JOHNSTON CI, ARNOLDA L, ABRAHAMS J, MCGRATH B: Role of vasopressin in experimental congestive cardiac failure. J Cardiovasc Pharmacol 8 (Suppl 7): S96-S100, 1986.

KASSAB S, KATO T, WILKINS FC, CHEN R, HALL JE, GRANGER JP: Renal denervation attenuates the sodium retention and hypertension associated with obesity. Hypertension 25: 893-897, 1995.

KIUCHI K, SHANNON RP, KOMAMURA K, COHEN DJ, BIANCHI C, HOMCY CJ, VATNER SF, VATNER DE: Myocardial beta-adrenergic receptor function during the development of pacing-induced heart failure. $J$ Clin Invest 91: 907-914, 1993.

LYMPEROPOULOS A, RENGO G, KOCH WJ: Adrenergic nervous system in heart failure: pathophysiology and therapy. Circ Res 113: 739-753, 2013.

MANN DL, BRISTOW MR: Mechanisms and models in heart failure: the biomechanical model and beyond. Circulation 111: 2837-2849, 2005.

MCMURRAY JJ, PFEFFER MA: Heart failure. Lancet 365: 1877-1889, 2005.

NAITOH M, SUZUKI H, MURAKAMI M, MATSUMOTO A, ARAKAWA K, ICHIHARA A, NAKAMOTO H, OKA K, YAMAMURA Y, SARUTA T: Effects of oral AVP receptor antagonists OPC-21268 and OPC-31260 on congestive heart failure in conscious dogs. Am J Physiol 267: H2245-H2254, 1994.

NIELSEN S, CHOU CL, MARPLES D, CHRISTENSEN EI, KISHORE BK, KNEPPER MA: Vasopressin increases water permeability of kidney collecting duct by inducing translocation of aquaporin-CD water channels to plasma membrane. Proc Natl Acad Sci U S A 92: 1013-1017, 1995.

PORT JD, BRISTOW MR: Altered beta-adrenergic receptor gene regulation and signaling in chronic heart failure. J Mol Cell Cardiol 33: 887-905, 2001.

RONA G: Catecholamine cardiotoxicity. J Mol Cell Cardiol 17: 291-306, 1985.

SCHIRMER SH, SAYED MM, REIL JC, UKENA C, LINZ D, KINDERMANN M, LAUFS U, MAHFOUD F, BOHM M: Improvements in left ventricular hypertrophy and diastolic function following renal denervation: effects beyond blood pressure and heart rate reduction. J Am Coll Cardiol 63: 1916-1923, 2014.

SCHMITZ W, BOKNIK P, LINCK B, MULLER FU: Adrenergic and muscarinic receptor regulation and therapeutic implications in heart failure. Mol Cell Biochem 157: 251-258, 1996.

SCHRIER RW: Role of diminished renal function in cardiovascular mortality: marker or pathogenetic factor? $J \mathrm{Am}$ Coll Cardiol 47: 1-8, 2006.

SCHRIER RW, ABRAHAM WT: Hormones and hemodynamics in heart failure. $N$ Engl J Med 341: 577-585, 1999.

SOBOTKA PA, KRUM H, BOHM M, FRANCIS DP, SCHLAICH MP: The role of renal denervation in the treatment of heart failure. Curr Cardiol Rep 14: 285-292, 2012.

TROISPOUX C, REITER E, COMBARNOUS Y, GUILLOU F: Beta2 adrenergic receptors mediate cAMP, tissue-type plasminogen activator and transferrin production in rat Sertoli cells. Mol Cell Endocrinol 142: 75-86, 1998. 
WEINBERG EO, SCHOEN FJ, GEORGE D, KAGAYA Y, DOUGLAS PS, LITWIN SE, SCHUNKERT H, BENEDICT CR, LORELL BH: Angiotensin-converting enzyme inhibition prolongs survival and modifies the transition to heart failure in rats with pressure overload hypertrophy due to ascending aortic stenosis. Circulation 90: 1410-1422, 1994.

YAO Y, FOMISON-NURSE IC, HARRISON JC, WALKER RJ, DAVIS G, SAMMUT IA: Chronic bilateral renal denervation attenuates renal injury in a transgenic rat model of diabetic nephropathy. Am J Physiol Renal Physiol 307: F251-F262, 2014.

ZHANG S, ZHANG F, SUN H, ZHOU Y, HAN Y: Enhanced sympathetic activity and cardiac sympathetic afferent reflex in rats with heart failure induced by adriamycin. J Biomed Res 26: 425-431, 2012.

ZHAO J, ARAKI N, NISHIMOTO SK: Quantitation of matrix Gla protein mRNA by competitive polymerase chain reaction using glyceraldehyde-3-phosphate dehydrogenase as an internal control. Gene 155: 159-165, 1995. 